\title{
Tourist mobility at coastal mass destinations: implications for sustainability
}

\author{
J. A. Ivars, M. A. Celdrán, A. Triviño \& J. F. Vera-Rebollo \\ University Institute for Tourism Research, \\ University of Alicante, Spain
}

\begin{abstract}
The aim of this paper is to analyse the spatial behaviour of mass tourism demand in coastal destinations and its implications from the point of view of sustainable tourism development. The paper is based on primary research carried out in one of the main Mediterranean tourist destinations, Benidorm (Spain). This research involved the use of Global Positioning Systems (GPS) devices for the tracking of a sample of 257 tourists (from Spain and United Kingdom). Although the research has an experimental basis, these advanced technologies allow new approaches to spatial analysis in order to achieve a better understanding of tourist mobility at coastal destinations. Until now, most studies of intradestination movements have been applied to urban and cultural destinations, where the points of interest and tourist routes are easily identifiable. However, spatial behaviour of mass tourism in coastal destinations has rarely been studied in detail using new tracking technologies. While tourist movements may seem, a priori, predictable, the identification of mobility patterns offers interesting results about the main characteristics of the tourist experience, the relationship with the urban model, the use of public and private spaces, the perception of the destination, and the differences between segments of demand. The conclusions of the study are relevant from the methodological and theoretical point of view, and include some recommendations for planning and destination management in the context of sustainability.

Keywords: tourist mobility, mass destination, spatial behaviour, sustainability, GPS, tracking tourist.
\end{abstract}




\section{Introduction}

Mobility constitutes an essential aspect of tourist activity, which has been examined from multiple perspectives (Duncan [1], Hall [2], Sheller and Urry [3]). Analyses of origin-destination and interdestination movements are more frequent than the study of intradestination movements owing to three reasons proffered by McKercher and Zoltan [4]: the need for greater precision in the data, the level of reliability of the information provided by the tourists and the lack of an adequate theoretical framework. However, the same authors point out that the first two limitations can be overcome via the use of electronic tracking devices, the appropriate use of which "could be revolutionary, pushing the boundaries of tourism studies and improving policy making, planning, and tourism management" (Shoval and Isaacson [5], p. 179).

The use of advanced tracking technologies has facilitated the performance of research into intradestination mobility by means of different approaches. The majority of the studies are centred on urban environments (Edwards and Griffin [6], Grinberger et al. [7], Lau and McKercher [8], Shoval and Isaacson [5]) and, to a lesser extent, on natural destinations (Donaire et al. [9], Hallo et al. [10]), fewer studies having been conducted in coastal environments, usually associated with sun and sand tourism. Obviously, these destinations do not pose the same problems with regard to mobility as the large urban agglomerations, whilst at the same time the behaviour of the demand tends to be more passive in comparison with urban destinations.

However, tourist movements are a key element for interpreting the characteristics of the tourism experience and, consequently, they provide fundamental information for the sustainable management of the destination. Furthermore, the use of time and space in beach destinations differs from the behaviour inherent to Urry's tourist gaze [11] to the extent that enjoyment of the destination is more experience-based. As expressed by Andrews [12] in his analysis of British tourism in Palmanova and Magaluf (Balearic Islands, Spain), Urry over-emphasises the gaze in privileging sight above the other senses. Tourist attractions in coastal destinations are perceived and enjoyed in a different way from those of typically urban and cultural destinations. This differentiated behaviour is connected with the type of tourism resources proposed by Caccomo and Solonandrasana (Botti et al. [13]), who distinguish between "discovery attractions" (D-attractions) and "escape attractions" (E-attractions) based on the relationship between satisfaction and length of stay. In the D-attractions (a museum, for example) the satisfaction of the demand reaches satiation after a time whilst in the E-attractions (which could include a beach) the satisfaction is lasting. In accordance with this approach, coastal destinations would comprise Eattractions, capable of generating a longer average stay and a relationship with the use of space and time that differs from that of urban and cultural destinations, clearly associated with D-attractions. 


\section{Aims and methodology}

The fundamental aim of this study is to analyse the mobility of the demand in a consolidated coastal destination of the Spanish Mediterranean (Benidorm) and to identify the implications from the point of view of the sustainability of tourism development. Furthermore, an instrumental objective of the research is to test the use of GPS devices in the analysis of the spatial behaviour of tourists.

The primary information for this study originates in a survey of Spanish and British tourists staying at hotels in the city of Benidorm during the months of May and June 2014, of whom a total of 179,311 were resident in Spain and 136,637 came from the United Kingdom. The sample comprised 257 tourists, 169 Spanish and 88 British. Its main aim was to determine the mobility of the demand at the destination during the day, for which a total of 20 GPS or datalogger model i-gotU GT-120 (65,000 waypoints) were used.

The process for obtaining the information was structured in three phases: delivery of the GPS to the tourists, downloading of the information and data management and processing. The GPS were delivered in two hotels, hotel A, located in the city centre, and hotel B, in Rincón de Loix, near to the Levante Beach. The GPS were delivered together with instructions regarding their use and a short survey was conducted to characterise the demand (basically: age, type of tourist - couple, family or group - type of board and whether it was their first stay in Benidorm) which enabled the analysis to be segmented, always in an experimental manner in view of the small size of the sample. The tourists received the GPS first thing in the morning and they were required to return them to the hotel reception at the end of the day. As an incentive for their cooperation, the tourists participated in a draw for a tablet. Every day, the routes of each of the GPS used were downloaded in GPX format and subsequently converted to .SHP format, in order to purge the data and to analyse them using ESRI ArcGis 10.1 software. After purging the information, 205 valid tracks were obtained (82 from hotel A and 123 from hotel B).

\section{Urban tourism model, sustainability and mobility at the destination}

The mobility of tourists within the destination is the result of the interaction of various factors among which Lew and McKercher [14] highlight the geomorphology of the destination, the spatial location of attractions and accommodation nodes, transport routes, mode and accessibility, tourist time budgets, tourist motivation and place knowledge. The city of Benidorm presents the singularity of its compact urban model, which concentrates within its municipal boundaries 73,768 registered inhabitants and 75,573 tourist beds (40,423 in hotels, 22,334 in tourist apartments and 12,816 on camp sites, according to the official data of the Valencian Tourism Board for 2015). It is one of the main hotel and tourism concentrations of the Mediterranean.

The urban tourism model of Benidorm has its origins in the Municipal Zoning Regulations Plan of 1956 which, after a series of modifications, define a model 
of a concentrated and vertical city. This planning model has enabled the configuration of a true leisure city since the beginning of the nineteen-seventies (Gaviria [15]) and which is currently recognised for its functionality and its economic and even environmental efficiency, to the extent that it presents a more reduced occupation of land than that of suburban developments (urban sprawl), more rational management of environmental vectors such as water, less use of private transport and a higher quality of the urban space (sea view from the city thanks to the structure of open building, pedestrian walkways, etc.) which make it more attractive for leisure activities (Bohigas [16], Ferrater and Martí [17], Iribas [18], Thomson Holidays [19]). Undoubtedly, the keys to Benidorm's success include the intensity of urban life and a personality defined on the basis of public space (Iribas [20]), a factor that is not unrelated to the capacity of Benidorm to adapt to the economic and tourism cycles from the nineteen-sixties to date (Ivars et al. [21]).

It is, therefore, a singular destination although, logically, it shares the dynamics inherent to mass beach destinations. The confrontation of destinations of this type with the principles of sustainable development, since such paradigm became consolidated in the nineteen-nineties, has given rise to different channels of interpretation. In summary, three fundamental approaches should be mentioned. In the first place, the unfounded dissociation between alternative tourism and mass tourism according to which the former is "innocent" and the latter is incompatible with sustainable development (Weaver [22]). Case studies show that alternative tourism can have considerable environmental and sociocultural impacts whilst mass destinations present interesting improvements from the point of view of sustainability, as well as the unavoidable need to evolve towards this paradigm in order to be competitive and contribute to local development in all its dimensions. In second place, the identification of sustainable development with an adaptive paradigm (Hunter [23]), without doubt a concept that is more applicable to mass destinations, would allow a grading of situations from very weak sustainability to very strong sustainability, giving as a real result a political discourse in favour of sustainability and progress classifiable at the weakest end of sustainability (Vera and Ivars [24]). In third place, the conception of sustainability as a process or path rather than an end or a utopian state, was proposed as a possibility to integrate the principles of sustainable development realistically in tourist destinations. However, authors such as Gössling et al [25] consider that the notion of sustainability as a transitory process is one of the greatest inherent weaknesses of the concept, responsible for the rhetorical use of sustainability, and they emphasise the need to define "an ideal end-state" with regard to some parameters of sustainability. However, in the scope of mass destinations, the association of sustainability with a process of change may serve to encourage the sustainable management of the destination, provided that benchmark target indicators are defined that make it possible to measure the progress towards sustainability and avoid the rhetorical use and abuse of this paradigm.

Climate change has led to a renewed and justified interest in the sustainable development of tourism. Gössling estimated that tourism contributes up to $5.3 \%$ 
of global greenhouse gas emissions from energy use, a share that is distributed as follows: transport (90\%), accommodation (6\%) and activities (4\%) (Becken and Hay [26]). The high percentage of transport refers basically to origin-destination travel. This fact is translated to the sustainability indicators relative to the impacts of transport. The European Tourism Indicator System (European Commission [27]) considers as core indicators the "Percentage of tourists and same day visitors using different modes of transport to arrive at the destination (public/private and type)" and the "Average travel (km) by tourists to and from home or average travel $(\mathrm{km})$ from the previous destination to the current destination" to promote short haul travel and an increase of sustainable transport options. An optional indicator is the "Percentage of visitors using local/soft mobility/public transport services to get around the destination". Therefore, in accordance with its relatively reduced impact, tourist mobility has a minimum presence in the sustainability indicators. However, its influence in the management of the destination should not be underrated in destinations with a significant concentration of demand, because sustainable mobility contributes to improving environmental parameters while enhancing the urban scene and the use of public spaces, with the consequent positive effect on the satisfaction of tourist demand.

\section{The spatial behaviour of tourists in Benidorm: results of the study using GPS}

The analysis of mobility comprises the on-site experience of the tourists, which is determined by three interconnected factors (Pearce [28]): resources (the physical or cultural setting), activities available for visitors and conceptions (the public meanings and understandings of what the place is about). In the case of Benidorm, the basic resources are the beach and the climate, the activities correspond to the leisure supply of the city and the conception of the place is clearly associated with a tourist area, a leisure city. These characteristics differ from those inherent to urban destinations and require new approaches for the analysis of mobility. In an urban destination, such as Hong Kong (Grinberger et al. [7]), 95\% of the tourists whose movements have been analysed keep their journeys to a minimum in order to have more time at the sites/activities that can be identified as points of interest. The time at the sites/activities is more important than the space. However, in studies applied to natural spaces the enjoyment of the space is more important than saving time to concentrate it on the sites or points of interest (Hallo et al. [10]). This behaviour presents clear analogies with beach destinations, where the tourist is not so conditioned by visits to a certain number of tourist attractions.

In Benidorm, the logic of intradestination movements is marked by a type of passive leisure activities according to a set of motivations of the demand with a predominance of rest/relaxation, sunbathing on the beach, unwinding and enjoying the atmosphere of the city (Benidorm Tourism Foundation [29]). The spatial interpretation of these motivations is represented in fig. 1 which shows a map with the frequentation of the main points of interest (POI) of the destination 


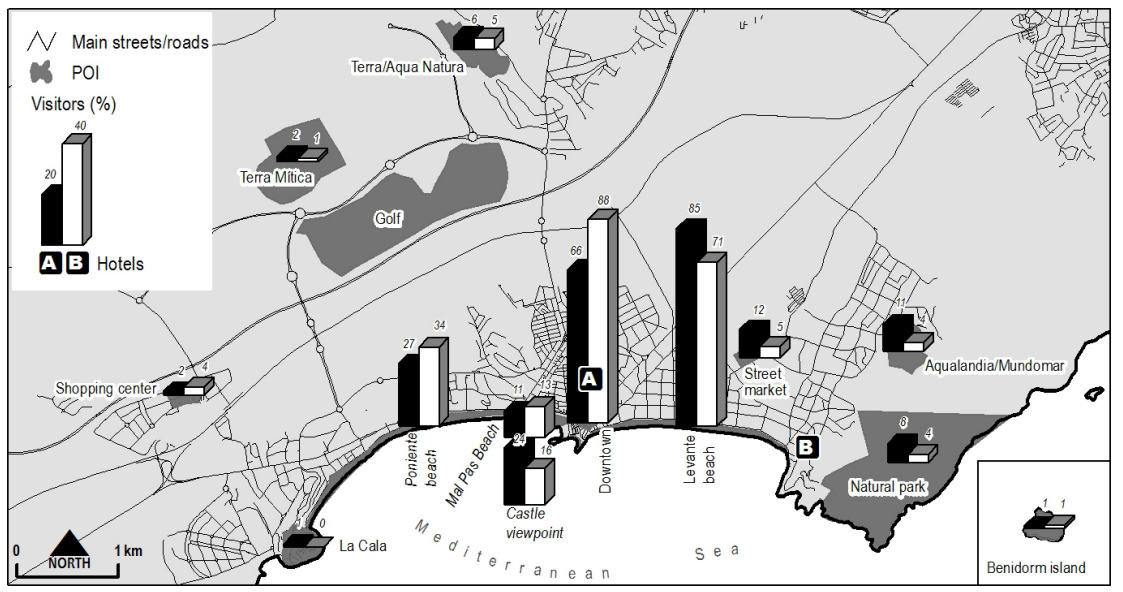

Figure 1: Map of frequentation of the POIs in Benidorm.

(\% of tourists who visit each POI). The distribution of the visits reflects two fundamental poles of attraction: Levante Beach and the town centre (Downtown), two public spaces that satisfy to a great extent the leisure needs of the demand (beach, promenades, shops, catering establishments, etc.). In second place are Poniente Beach and the Castle Viewpoint (Mirador del Canfali). Proximity to the hotels constitutes one explanatory factor but this is not so important in the case of hotel $\mathrm{B}$. The daily movements reach a significant distance. $75 \%$ of the tourists of hotel A cover a maximum distance of 3.5 kilometres, a distance that increases to 4.2 kilometres in the case of hotel B. These distances are covered on foot, without the need to use motor vehicles, an important aspect from the point of view of sustainability. The movements mainly take place within the compact city, with a low percentage of visits to the POIs of the urban surroundings (theme parks, Sierra Helada natural park, etc.). Undoubtedly, intradestination movements predominate. In addition, information regarding the trips that the tourists have taken, or intend to take, is obtained via an open question on the questionnaire administered prior to delivery of the GPS.

Fig. 2 shows a map with the points that the tourists state they have visited or intend to visit. It should be taken into account that the average stay of the tourists accommodated at hotels in Benidorm is 5.5 days in May and 5.9 days in June (National Institute of Statistics) so that this information complements that obtained from the use of the GPS during one day of stay to obtain a more accurate view of the mobility in the destination. Again, the percentage of town centre locations, which are perceived as a trip, stands out, as distinguished from the beaches, probably conceived as a space for more recurrent frequentation during their stay. The percentage of visits to theme and water parks increases, although the figures are still modest (around 10\% each). Likewise, supradestination movements, marginal in the information obtained via GPS, increase to $13 \%$. Fig. 2 ratifies the concentration of the movements in the compact city. To understand them better an analysis has been conducted of the frequentation of the streets of the city. 


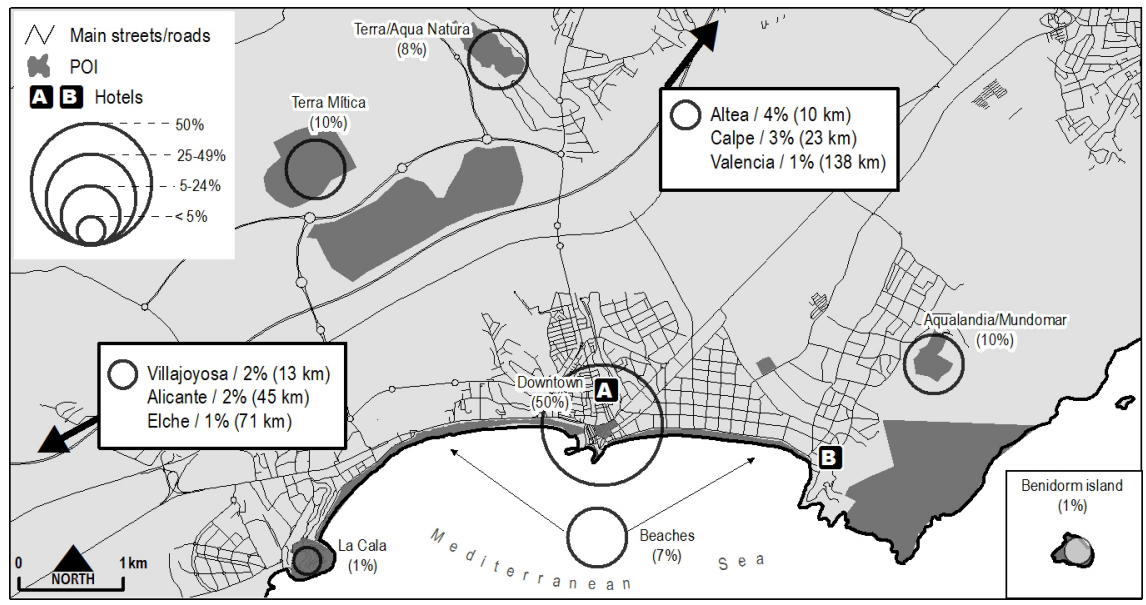

Figure 2: Map of points that tourists have visited or intend to visit during their stay in Benidorm (\%).

Fig. 3 represents the percentages of tourists of hotel B who pass along the streets of Benidorm, differentiating between British and Spanish visitors. In both cases the logical movements of proximity are observed together with the importance of the coastal front of the Levante Beach and the streets located slightly further inland or "second line", as well as the streets of the town centre. However, the behaviour of the British visitors presents some differences, such as greater frequentation of a "third line" of streets (calle Gerona, fundamental axis of the area known as the English zone) and the transit along a higher number of streets in the town centre.

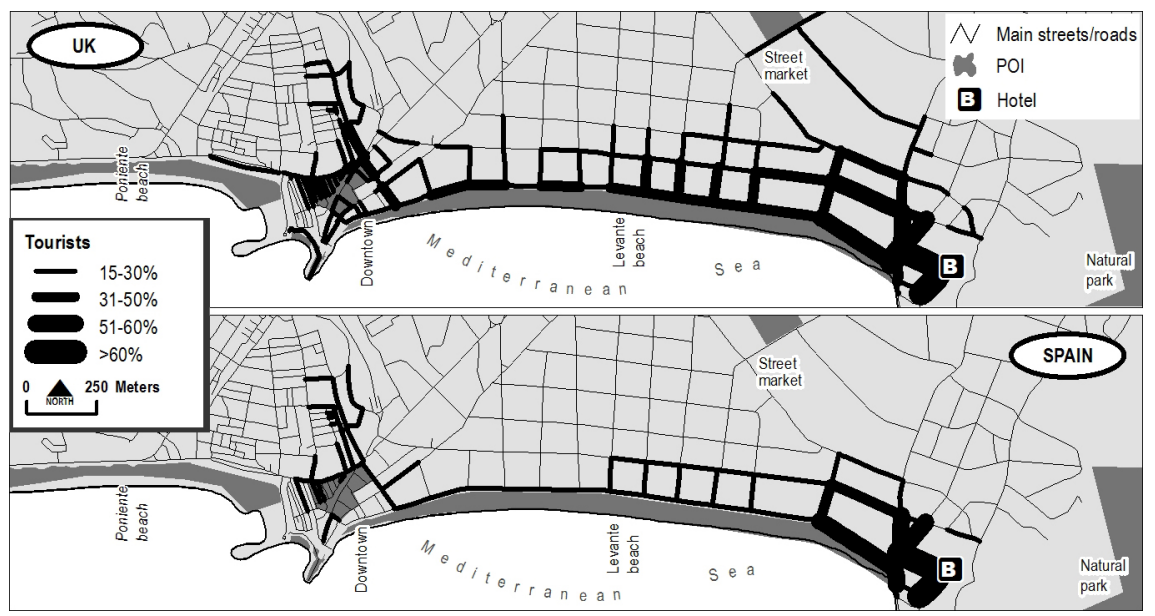

Figure 3: Map of frequentation of the streets by British and Spanish tourists of hotel B. 
These maps illustrate the fact that the urban space of Benidorm constitutes a fundamental part of the tourist experience. Despite the fact that the majority of the sample analysed had full board and all-inclusive accommodation, the tourists enjoy the public space and do not confine themselves to their hotels, supporting a considerable catering and commercial supply and favouring a reduction in the seasonal nature of tourist activity by not depending solely and exclusively on the beach (in 2014, the mean rate of hotel occupancy in Benidorm was 75\%). This behaviour is possible thanks to a dense urban model, with open blocks, where the limit between the public (the street) and the private (buildings) is permeable and dynamic, as suggested by Gehl [30]. This is, to use the expression of Iribas [20], the triumph of the street, of the intensity of use of the urban space that this author associates with the occupation of recesses between buildings for profit-making uses (shops, bars, restaurants), a characteristic schema of the urban expansion of the Levante Beach of Benidorm.

\section{Conclusions}

The application of GPS to the study of mobility represents significant progress compared to traditional methods of analysis. Its possibilities are varied, but so too are its limitations. On the one hand, from the tourist side, we have identified users who switch off the device within the first 30 minutes. However, 91\% pass the threshold of 4 hours with the GPS switched on. We have also reached the conclusion that $2 \%$ of the receivers provided doubtful data since the cloud of points is concentrated around the hotels. With regard to the device used, the limitations detected are concentrated on position errors that respond to circumstances already described in other similar studies. The most common errors are misplaced and missing points and the problems with the collected data can be in temporal or spatial dimensions or in both dimensions simultaneously (Shoval and Isaacson [5]). We estimate that the most frequent error is that of misplaced points as a consequence of losses in the quality of the GPS signal. The points that appear in built-up areas respond to the problematic reception of the GPS signal. This occurs as a result of a decrease in the number of visible satellites, for example when the person is indoors, as well as to the effect of the multipath signal in narrow streets with very close buildings. In tourist destinations such as Benidorm open planning favours the reduction of errors of this type. With regard to the time dimension of the data, registers that share the same time have been observed for one tracked person. This receiver error does not compromise the integrity of the spatial database since the spatial behaviour of the track is coherent. However, it makes it difficult to study the time spent by the tourists in specific locations.

The implications of mobility with regard to sustainable development respond directly to the urban tourism model. The compact city structure with a critical mass of commercial accommodation (basically hotels), adequate public spaces (promenades and pedestrian streets, spacious pavements, etc.) and an attractive supply of services favours pedestrian mobility, the development of a significant economic activity based on tourist consumption, and an inclusive type of tourism 
where residents and tourists of different types mix naturally. Thus, the good aspects of this model are apparent on an environmental, economic and sociocultural level, unlike diffuse urban developments, generally based on second homes, or enclaves, of a resort type, where the tourism experience is almost exclusively confined to the place of accommodation. However, although a high level of intradestination mobility is noticed, it is interesting to analyse the distribution of tourist expenditure in relationship with the supply of services and the real capacity of the tourist demand to influence the local productive fabric, especially when processes of deterioration are noticed with regard to the quality of the commercial and gastronomic supply that may have a negative repercussion on the image and attractiveness of the destination.

Furthermore, the bid by the city to act as a leisure space must be compatible with the recovery and promotion of urban identity. This balance has not been achieved in the centre of the city, the traditional town centre, which presents a high level of frequentation by tourists despite the fact that the preservation of the cultural heritage and its enhancement for tourism has not been a priority. Although, fortunately, the urban marginalisation processes present in other tourist destinations are not apparent, processes of banalisation of the space are evident and they hinder the possibilities of attracting new segments of demand and other commercial segments with greater added value.

From the point of view of the planning and management of the destination, tourist mobility is indicative of the scant diversification of the tourist products in the destination and the motivational, and also spatial, concentration of the demand in the compact city. The most important public operation of renovation of the destination, the building of the Terra Mítica theme park, has not achieved the expected results. Although it is undeniable that theme and leisure parks play an important role in the attractiveness of the destination, there is still a margin for improvement for recruitment of the demand accommodated at the hotels. Moreover, the natural spaces, in particular the Sierra Helada Natural Park, do not arouse the interest of the demand. In the light of this situation, it is necessary to continue to strengthen the strategies for diversification, whilst at the same time acting to improve the central tourism space, which continues to be the driving force of the destination.

Lastly, the information systems for the management of the destination must incorporate the possibilities offered by information and communication technologies. The smart destination focus, on which the local authorities have started working, is of particular interest in order to offer new services and utilities to tourists (information, reservation, purchasing, offers, etc.) and to monitor their behaviour at the destination using various methods and instruments: mobile applications, monitoring of social media, urban sensors, monitoring of means of payment, wearables, etc. A new scenario is therefore opening up for the analysis of mobility at the destination, allowing a greater integration of variables that will lead to more efficient and sustainable tourism management. However, as in the case of GPS, the use of these new techniques will require a considerable number of adjustments in view of the complexity inherent to the analysis of intradestination tourist mobility. 


\section{Acknowledgements}

This research has been carried out within the framework of the project "New approaches for tourism destinations planning and management: conceptualization, case studies and problems. Definition of smart tourist destinations models" (CSO2014-59193-R) under the Spanish National R\&D\&I Plan financed by the Ministry of Economy and Competitiveness.

\section{References}

[1] Duncan, T., The 'Mobilities Turn' and the Geography of Tourism. The Routledge Handbook of Tourism Geographies, ed. Julie Wilson, Routledge: Oxon, pp. 113-119, 2012.

[2] Hall, C.M., Tourism: Rethinking the Social Science of Mobility, PrenticeHall: Harlow, UK, 2004.

[3] Sheller, M., \& Urry, J., The new mobilities paradigm. Environment and Planning A, 38(2), pp. 207-226, 2006.

[4] McKercher, B. \& Zoltan, J., Tourist Flows and Spatial Behavior. The Wiley-Blackwell Companion to Tourism, eds Lew, A.A, Hall, C.M. \& Williams, A. Wiley Blackwell: Oxford, pp. 33-44, 2014.

[5] Shoval, N., \& Isaacson, M., Tourist Mobility and Advanced Tracking Technologies. Routledge Advances in Tourism 19, Routledge: New York, 2010.

[6] Edwards, D., \& Griffin, T., Understanding tourists' spatial behaviour: GPS tracking as an aid to sustainable destination management. Journal of Sustainable Tourism, 21, pp. 580-595, 2013.

[7] Grinberger, A. Y., Shoval, N., \& McKercher, B., Typologies of tourists time-space consumption: a new approach using GPS data and GIS tools. Tourism Geographies, 16(1), pp. 105-123, 2014.

[8] Lau, G., \& McKercher, B., Understanding Tourist Movement Patterns in a Destination: A GIS Approach. Tourism and Hospitality Research, 7, 3949, 2006.

[9] Donaire, J.A., Galí, N. \& Royo-Vela, M., El Uso de GPS Para El Análisis Del Comportamiento Espacio-Temporal de Los Turistas. Pre-Test En El Valle de Boí. Cuadernos de Turismo, 35, pp. 117-131.

[10] Hallo, J. C., Beeco, J. A., Goetcheus, C., McGee, J., McGehee, N. G., \& Norman, W. C., GPS as a Method for Assessing Spatial and Temporal Use Distributions of Nature-Based Tourists. Journal of Travel Research, 51(5), pp. 591-606, 2012.

[11] Urry, J. The Tourist Gaze: Leisure and Travel in Contemporary Societies, Sage: London, 1990.

[12] Andrews, H., The British on Holiday: Charter Tourism, Identity and Consumption. Tourism and Cultural Change, Channel View Publications: Tonawanda (New York), 2011.

[13] Botti, L., Peypoch, N., \& Solonandrasana, B., Time and tourism attraction. Tourism Management, 29(3), pp. 594-596, 2008. 
[14] Lew, A., \& McKercher, B., Modeling tourist movements: A local destination analysis. Annals of Tourism Research, 33(2), pp. 403-423, 2006.

[15] Gaviria, M., Benidorm, Ciudad Nueva, Editora Nacional: Madrid, 1977.

[16] Bohigas, O., Contra la incontinencia urbana. Reconsideración moral de la arquitectura y la ciudad, Electa: Barcelona, 2004.

[17] Ferrater, C. \& Martí, X., Benidorm, Paseo Marítimo Playa Poniente, Actar: Barcelona, 2011.

[18] Iribas, J. M., Benidorm, Manual de uso, in MAAS, Costa Ibérica. Hacia la ciudad del ocio: Actar, Barcelona, 2000.

[19] Thomson Holidays. Sustainable holiday futures, Online http:// communicationcentre.thomson.co.uk/

[20] Iribas, J. M., Aprendiendo de Benidorm. Pedro Zaragoza, 1922-2008. Arquitectura Viva, 117, p. 128, 2007.

[21] Ivars, J., Rodríguez, I. \& Vera, J. F. The evolution of mass tourism destinations: New approaches beyond deterministic models in Benidorm (Spain). Tourism Management, 34, pp. 184-195, 2013.

[22] Weaver, D. Enlightened Mass Tourism as a 'Third Generation' Aspiration for the Twenty-First Century." The Practice of Sustainable Tourism. Resolving the Paradox, edited by Hugues, M., Weaver, D. and Pforr, Ch. Routledge: Oxon, 2015.

[23] Hunter, C., Sustainable tourism as an adaptive paradigm. Annals of Tourism Research, 24(4), pp. 850-867, 1997.

[24] Vera, J.F. \& Ivars, J., Measuring sustainability in a mass tourist destination: pressures, perceptions and policy responses in Torrevieja, Spain. Journal of Sustainable Tourism, 11, 2-3, pp. 181-203, 2003.

[25] Gössling, S., Hall, C. M. \& Weaver, D. (eds), Sustainable Tourism Futures: Perspectives on Systems, Restructuring and Innovations, Routledge: New York, UK, 2009.

[26] Becken, S. \& Hay, J. E., Tourism and Climate Change: Risks and Opportunities. Climate Change, Economy and Society, Channel View Publications: Clevedon, Buffalo, Toronto, 2007.

[27] European Commission, DG Enterprise and Industry, European Tourism Indicator System for Sustainable Destinations, European Union: Brussels, 2013.

[28] Pearce, P.L. Tourist Behaviour: Themes and Conceptual Schemes. Aspects of Tourism (Book 27). Channel View Publications: Clevedon, Buffalo, Toronto, 2005.

[29] Fundación Turismo Benidorm, (Benidorm Tourism Foundation), Plan de Marketing Turístico de Benidorm 2011-2015, Innova Management: Benidorm, 2010.

[30] Gehl, J., Cities for People, Island Press: Washington, DC, 2010. 